Article

\title{
Application of a MOGA Algorithm and ANN in the Optimization of Apple Drying and Rehydration Processes
}

\author{
Radosław Winiczenko, Agnieszka Kaleta and Krzysztof Górnicki * \\ Institute of Mechanical Engineering, Warsaw University of Life Sciences-SGGW, 164 Nowoursynowska Str., \\ 02-787 Warsaw, Poland; radoslaw_winiczenko@sggw.edu.pl (R.W.); agnieszka_kaleta@sggw.edu.pl (A.K.) \\ * Correspondence: krzysztof_gornicki@sggw.edu.pl
}

Citation: Winiczenko, R.; Kaleta, A.; Górnicki, K. Application of a MOGA Algorithm and ANN in the Optimization of Apple Drying and Rehydration Processes. Processes 2021, 9, 1415. https://doi.org/10.3390/ pr9081415

Academic Editor: Dariusz Dziki

Received: 12 July 2021

Accepted: 12 August 2021

Published: 16 August 2021

Publisher's Note: MDPI stays neutral with regard to jurisdictional claims in published maps and institutional affiliations.

Copyright: (c) 2021 by the authors. Licensee MDPI, Basel, Switzerland. This article is an open access article distributed under the terms and conditions of the Creative Commons Attribution (CC BY) license (https:/ / creativecommons.org/licenses/by/ $4.0 /)$.

\begin{abstract}
The aim of the study was to estimate the optimal parameters of apple drying and the rehydration temperature of the obtained dried apple. Conducting both processes under such conditions is aimed at restoring the rehydrated apple to the raw material properties. The obtained drying parameters allow the drying process to be carried out in a short drying time (DT) and at low energy consumption (EC). The effect of air velocity $\left(v_{d}\right)$, drying temperature $\left(T_{d}\right)$, characteristic dimension $(C D)$, and rehydration temperature $\left(T_{r}\right)$ on rehydrated apple quality was studied. Quality parameters of the rehydrated apple as: color change (CC), mass gain ratio (MG), solid loss ratio (SL), volume gain ratio (VG) together with DT and EC were taken into consideration. The artificial neural network was used for modeling of rehydrated apple quality parameters, DT, and EC. A multi-objective genetic algorithm was developed in order to optimize parameters of the drying and rehydration processes. The simultaneous minimization of CC, SL, DT, EC, and the maximization of MG and VG were considered with the following drying and rehydration processes parameters: $T_{d}: 50-70{ }^{\circ} \mathrm{C}, v_{d}: 0.01-2 \mathrm{~m} / \mathrm{s}, T_{r}: 20-70{ }^{\circ} \mathrm{C}$. The best solution has been found at drying temperature $56.1^{\circ} \mathrm{C}$, air velocity $1.3 \mathrm{~m} / \mathrm{s}$, characteristic dimension $2.0 \mathrm{~mm}$, and rehydration temperature $59.2{ }^{\circ} \mathrm{C}$. This apple drying and rehydration resulted in $\mathrm{MG}=3.51, \mathrm{SL}=0.57, \mathrm{VG}=4.77, \mathrm{CC}=11.2, \mathrm{DT}=5.4 \mathrm{~h}$, $\mathrm{EC}=159.8 \mathrm{GJ} / \mathrm{kg}$. The parameters of apple drying and rehydration processes can be recommended for the industry application.
\end{abstract}

Keywords: apple; artificial neural network; drying; genetic algorithm; optimization; rehydration

\section{Introduction}

Apples are one of the basic horticultural products and apple plantations are present all over the world. Poland is a significant global producer of these fruits. Apples are low caloric fruits and play a significant role in the human diet. They typically contain about $86 \%$ of $\mathrm{H}_{2} \mathrm{O}, 12-14 \%$ of carbohydrate, $0.3 \%$ of protein, $0.2 \%$ of lipids, $2 \%$ of dietary fiber and many very important minerals $(\mathrm{Ca}, \mathrm{Mg}, \mathrm{K})$. Apples may help in reducing the effect of asthma and cholesterol levels [1-3]. Dried apples (instead of fresh) may be used in many processed or ready-to-eat foods due to advantages such as the convenience of transportation, storage, preparation, and use. Dehydrated apples sometimes are rehydrated before consumption or further processing.

Drying is one of the most common and important unit operation applied in such industrial sectors producing solid products as food, pharmaceutical, and chemical. Drying generally is defined as removing of fluid or moisture from wet body by changing the moisture into a gaseous phase [4,5]. Drying belongs to the processes that need high energy because of the high value of the latent heat of water evaporation and low energy efficiency of dryers. Moreover, the energy consumption and drying efficiency depend highly on the drying methods and the materials being dried [6]. The dryers consume approximately $12 \%$ of the energy employed in manufacturing processes, whereas on average about $10 \%$ of the energy used in the food industry is allocated to the drying process $[4,7,8]$. About 
$50-70 \%$ of energy employed in wood process is used for drying [9]. It is stated that in such manufacturing processes where material dehydration is needed, the drying cost amounts to $60-70 \%$ of the total cost [4]. Therefore, increasing efficiency of drying systems for good quality of dried products has been an important research area of the drying industry.

Many papers related to the drying of apple cubes have been found in the literature. Dependence of temperature, relative humidity, velocity, and material size of thin-layer apple (var. Idared) cubes on their drying kinetics [10] as well as the effects of the drying variables on the quality characteristics such as shrinkage and color of dried apple were evaluated [11]. The kinetics of apple cubes drying with the convective method was described by Figiel [12]. According to the author, apple cubes dried with the combined method demonstrated better rehydrating properties manifested by absorption capacity, dry-mater-holding capacity, and rehydration ability as compared to the apples dried only with the use of the convective method.

Many methods of drying apples such as using heat pump, vacuum-microwave, or intermittent techniques can be used in commercial scale for modification of the texture attributes according to potential consumer preferences. However, heat pump vacuummicrowave method is the best drying technique to produce crispy and healthy apple snack with nice appearance, as reported by [13]. Pasławska et al. [14] investigated the possibility of using the vacuum impregnation as a pre-treatment before drying apple cubes. Apple cubes were dried by convective drying and microwave-vacuum drying. The above drying methods allow to obtain the dried apples characterized by the reduced compressive resistance, increased resistance to cutting, and less elasticity in relation to the raw material. Diamante and Yamaguchi [15] investigated the effects of temperature, air velocity, and loading density on the drying of infused apple. They optimized drying temperature, air velocities, and loading densities, and drying times for hot air drying using response surface method. Assis et al. [16] studied the effects of the osmotic pre-treatment with sucrose or sorbitol solutions and different drying methods on the rehydration kinetics of apple cubes. Samples were dried by hot air at $70^{\circ} \mathrm{C}$, by microwave at $500 \mathrm{~W}$, and by freeze-drying. The rehydration rate and the rehydration capacity of the apple cubes dried by these methods were not affected by the solute used in the pre-treatment with sucrose and sorbitol. Product quality is becoming very important in the storage and drying processes $[17,18]$. The wide variety of dried products and the interesting concern for meeting energy conservation and product quality emphasize the necessity of dehydration optimization [19]. The rehydration capability is one of the quality attributes of some food materials whereas some dried products must be rehydrated before further processing or consumption [20].

Rehydration is a complicated process that indicated the degree of physical and chemical changes occurring during processing (treatments preceding drying, dehydration, and rehydration) $[21,22]$. It can be accepted that rehydration indicates the degree of structural and cellular damage caused to the product $[23,24]$. Rehydration can be described as a process of moistening dry material, mainly using water. Three simultaneous processes occur during rehydration, namely: the imbibition of moisture into dehydrated product, the swelling, and the leaching of solubles (sugars, acids, minerals, and vitamins) [21,25]. Generally speaking, rehydration is a complex mass-transfer process that consists of several physical mechanisms, including absorption of water, internal diffusion, convection inside the large open pores and at the surface of product, and relaxation of solid structure [26].

Conventional optimization algorithms using linear and non-linear programming sometimes have difficulty in finding the global optima or in case of multi-objective optimization, the Pareto front. A lot of research has now been directed toward genetic algorithms (GAs) to solve multi-objective optimization problems. Genetic algorithms are a biologically inspired highly parallel mathematical search algorithm pioneered by Holland. GAs generate entire population of points, each with associated fitness value, tests each point independently, and combines qualities from existing points to form a new population, containing improved points [27]. They compute the fitness value using the information concerning the quality of the solution produced by the members of the population (ob- 
jective function values) [28]. This adaptive evolutionary learning process relates to the evolutionary selection procedure of genetic chromosomes. Genetic Algorithms rely on the Darwinian principle of reproduction and survival of the fittest and natural genetic operations like mutation [29,30]. Multi-objective genetic algorithm (MOGA) optimization involves minimizing or maximizing multiple objective functions subject to a set of constraints. The basic steps of the multi-objective genetic algorithm were described in detail by authors [31].

In literature the multi-objective optimization of apple drying was done [31,32]. The simultaneous minimization of color difference, maximization of the volume ratio, and water absorption capacity was successfully applied. Authors found optimal solution: drying air velocity and temperature [31]. The simultaneous minimization of color difference and volume ratio and the maximization of water absorption capacity were considered. The optimal solution: drying air temperature, air velocity, rehydration temperature and kind of rehydrating medium were conducted in [32].

Determining the optimal parameters of drying is important for solving the problems of product quality and optimizing the quantity of energy consumed during dehydration. However, to our knowledge, there are fewer or no items in the literature about this problem. Darvishi et al. [33] conducted the optimization of dehydration process of sawory leaves, taking into consideration criteria such as: drying variables (drying air temperature, drying air velocity, infrared power density), minimum drying time, energy consumption, color change, and maximum rehydration and moisture extraction ratios. There are no information in the literature about optimization of the quantity of energy consumed during apple dehydration.

The study aims to estimate the optimal parameters of apple drying and the rehydration temperature. Conducting both processes under such conditions ensures the restoration of the raw material properties of rehydrated apples. The obtained parameters allow the drying process to be carried out in a short drying time (DT) and at low energy consumption (EC).

\section{Materials and Methods}

\subsection{Materials}

Apples var. Ligol, bought from Warsaw market (Poland), were used for conducting the experiments. The initial moisture content of the apples was approximately $5.7 \mathrm{~kg}$ water $/ \mathrm{kg}$ dry mass ( $0.85 \mathrm{~kg}$ water $/ \mathrm{kg}$ wet mass). They were washed, peeled, and cut into slices ( $3 \pm 1$ and $10 \pm 1 \mathrm{~mm}$ thickness) or cubes (10 $\pm 1 \mathrm{~mm}$ thickness).

The characteristic dimension $(C D)$ of apples was calculated as [34]:

- For slices $C D=s$;

- $\quad$ For cubes $\frac{1}{C D^{2}}=\frac{3}{s^{2}}$;

where $s(\mathrm{~mm})$ is the half of the slice thickness and cube thickness, respectively.

\subsection{Drying}

The apple samples were dried using forced convection in a laboratory dryer constructed in the Institute of Mechanical Engineering, Warsaw University of Life Sciences, Warsaw, Poland. The dryer consisted of an airflow control unit, an electrical fan, a heating and heating control unit, the drying chamber, and a measurement sensor. The airflow control unit regulated the velocity of the drying air flowing through the drying chamber. The desired air temperature was obtained by electrical resistance heating and controlled by the heating control unit. The drying air velocity and temperature were measured directly in the drying chamber. The samples were placed on a stainless steel wire tray of known weight. The weighing of samples was done manually outside the chamber. Prior to placing the apples in the dryer, the system was run for at least one hour to obtain stable conditions.

The drying air velocity $\left(v_{d}\right)$ amounted to $0.5 \mathrm{~m} / \mathrm{s}$ and $2.0 \mathrm{~m} / \mathrm{s}$. The drying air temperatures were following $\left(T_{d}\right): 50,60$, and $70^{\circ} \mathrm{C}$. The final moisture content of the dried apples was approximately $0.1 \mathrm{~kg}$ water $/ \mathrm{kg}$ dry mass ( $0.09 \mathrm{~kg}$ water $/ \mathrm{kg}$ wet mass). The dehydration processes were conducted, in given conditions, in triplicate. The drying time 
(DT) was measured using a stopwatch (1 s accuracy). The dried material (given drying conditions) was mixed and next stored in a container (no exposure to sunlight) for a week at the temperature amounted to $20{ }^{\circ} \mathrm{C}$.

\subsection{Rehydration}

The process of dried apple rehydration was conducted in distilled water at following temperatures $\left(T_{r}\right): 20,45$, and $70{ }^{\circ} \mathrm{C}$. The experiments lasted from $3\left(T_{r}=70{ }^{\circ} \mathrm{C}\right)$ to $6 \mathrm{~h}$ $\left(T_{r}=20^{\circ} \mathrm{C}\right)$ and was carried out in triplicate. The initial mass of the sample (dried apples) showing rehydration was approximately $10 \mathrm{~g}$. The dried apples mass (at beginning of the process) to the mass of distilled water ratio amounted to 1:20. The water temperature was constant, and it was not stirred during rehydration.

\subsection{Mass and Volume}

The mass of the sample $(m)$ (dried and rehydrated apple, dry matter) was measured using an electronic scale WPE 300 (RADWAG, Radom, Poland; $\pm 0.001 \mathrm{~g}$ accuracy). The apple dry matter was determined before and after rehydration according to AOAC standards [30]. The mentioned measurements were conducted in three replicates. The maximum relative error in the determination of the mass amounted to $0.1 \%$.

The volume of the sample $(V)$ (dried and rehydrated apple) was measured using the buoyancy method in petroleum benzine [31]. The volume measurement was conducted in triplicate. The maximum relative error in the determination of the volume amounted to $5 \%$.

\subsection{Color}

The scanner (CanoScan 5600F, Canon Inc., Tokyo, Japan, $4800 \times 9600$ dpi) was used to the color determination of fresh and rehydrated apple samples. The images were loaded into the sRGB color space, and then the mean brightness of pixels in each RGB channel of the image was taken to express color parameters. The mean RGB values were linearly transformed to CIE XYZ color space and then nonlinearly converted to CIELab coordinates. The values of reference for the color parameters $X Y Z$, at the standard observer of $10^{\circ}$ and illuminant D50, were 96.72, 100, 81.43, respectively [35]. According to [36], the Chroma (C) and the hue angle $(\mathrm{h})$ specific for CIELCh color space were defined. Details of the color measurement can be found in [31].

\subsection{Energy Consumption EC}

The energy consumed during dehydration per $\mathrm{kg}$ of dried apples (EC) is defined as [37-39]:

$$
E C=\frac{E_{Q}+E_{W}}{m_{d}}
$$

where: $E_{Q}(\mathrm{GJ})$ is the energy needed for heating the drying air, $E_{W}(\mathrm{GJ})$ is the energy needed to drive the drying air through the dryer, and $m_{d}(\mathrm{~kg})$ is the mass of the obtained dried apples,

$$
\begin{gathered}
E_{Q}=A v \rho C \Delta T \tau \\
E_{W}=\Delta P v A \tau
\end{gathered}
$$

where: $A\left(\mathrm{~m}^{2}\right)$ is the cross-section area, $v(\mathrm{~m} / \mathrm{s})$ is the air velocity, $\rho\left(\mathrm{kg} / \mathrm{m}^{3}\right)$ is the air density, $C(\mathrm{GJ} /(\mathrm{kg} \mathrm{K}))$ is the air specific heat, $\Delta T(\mathrm{~K})$ is the temperature difference, $\tau(\mathrm{s})$ is the drying time, and $\Delta P(\mathrm{GPa})$ is the pressure drop.

\subsection{Quality Parameters $Q P$}

The color change (CC), mass gain ratio (MG), solid loss ratio (SL), and volume gain ratio (VG) were applied for the quality determination of rehydrated apple samples. The quality parameters (QP) are defined in Table 1. 
Table 1. Equations for quality parameters calculating of rehydrated apple.

\begin{tabular}{|c|c|}
\hline Parameters & Equation No. \\
\hline $\begin{array}{c}\mathrm{CC}=\sqrt{\left(\frac{\Delta L}{K_{L} S_{L}}\right)^{2}+\left(\frac{\Delta C}{K_{C} S_{C}}\right)^{2}+\left(\frac{\Delta H}{K_{H} S_{H}}\right)^{2}} \\
\mathrm{MG}=\frac{m_{r}-m_{d}}{m_{d}} \\
\mathrm{SL}=\frac{m_{d m d_{d}-m_{d m r}}}{m_{d p^{r} r}} \\
\mathrm{VG}=\frac{V_{r}}{V_{d}}\end{array}$ & $\begin{array}{l}(4) \\
(5) \\
(6) \\
(7)\end{array}$ \\
\hline $\begin{array}{l}\text { where: } S_{L}, S_{C}, S_{H} \text {-the weight functions (adjusting } \\
\left.S_{C}=1+0.045 C, S_{H}=1+0.015 C\right), K_{L}, K_{C}, K_{H} \text {-the vari } \\
\text { difference between tested }(T) \text { and standard (s) samples in } \\
\left.\Delta C=C_{T}-C_{S}, \Delta H=2 \sqrt{C_{T} \cdot C_{S}} \cdot \sin \left(\frac{\Delta h}{2}\right)\right), m \text {-mass }(k \\
\text { dry matter, and rehydrated, respectively. }\end{array}$ & $\begin{array}{l}\text { structure of CIELab }\left(S_{L}=1 \text {, }\right. \\
\text { ce conditions, } \Delta L, \Delta C, \Delta H-\text { the } \\
\text { (C), and hue }(H)\left(\Delta L=L_{T}-L_{S}\right. \\
\text { bscripts } d, d m \text {, and } r \text { refer to dry, }\end{array}$ \\
\hline
\end{tabular}

\subsection{QP, DT, and EC Modeling Using the Artificial Neural Network}

Artificial neural networks (ANN) comprise of autonomous processing elements (neurons) with associated weights and activation functions. These neurons are simplified computational models based on our understanding of biological neurons. The weights represent the relationship between the neurons [40]. Various architectures including feed forward neural networks with associated learning schemes such as back-propagation have been proposed using networks of these neurons. Variants include recurrent networks and radial basis function networks. The learning schemes provide a means of modifying the weights [41]. Stone-Weierstrass and Kolmogorov theorems prove that feed forward neural networks can approximate continuous functions to the desired degree of accuracy [42]. Moreover, the ANN can be used to learn non-linear relationships in a given data set.

The artificial neural network was used to QP, DT, and EC modeling. The ANN task was to map input variables: $T_{d}, v, C D$, and $T_{r}$ (parameters of the drying and rehydration processes) on to six output variables: CC, MG, SL, VG (quality parameters), DT and EC to obtain the lowest mean squared error (MSE) and high: correlation coefficient (R) and adjusted R-square.

Values of input and output parameters were normalized in the range from 0 to 1 (division by using their maximum values: 70, 2, 5.8, 70, 42.02, 3.6, 0.67, 4.8, 9.25, 397 for $T_{d}$, $v, C D, T_{r}, \mathrm{CC}, \mathrm{MG}, \mathrm{SL}, \mathrm{VG}, \mathrm{DT}$ (in h) and EC (in GJ/kg), respectively). Data cases have been randomly divided into training $(70 \%)$, testing $(15 \%)$, and validation $(15 \%)$ sample sets. A feed forward neural network with a backpropagation algorithm was employed. The MATLAB Neural Networks Toolbox R2018a software with Lavenberg-Marquardt algorithm for training was used.

\subsection{Optimization Problem}

A genetic algorithm (GA) was chosen to optimize the process parameters. GA is a powerful optimization tool especially in irregular experimental regions. In the process of drying and rehydration, complex and highly nonlinear phenomena take place [43]. Therefore, it is easy to estimate relationships between the input and the output of this complex system using ANN and GA techniques. The main characteristic of GA over the other optimization techniques is that they operate simultaneously with a huge set of searching points to find optimal architecture instead of a single point [28]. GA performs better than response surface methodology (RSM) when a large number of experiments are affordable.

The multi-objective optimization (MOO) task was aimed to define the set of optimal conditions of the dehydration and rehydration processes. The following functions: CC, DT, EC, and SL were minimized whereas MG and VG ones were maximized according to 
constraints on the drying $\left(T_{d}, v, C D\right)$ and rehydration $\left(T_{r}\right)$ parameters. The Equation (8) presents the mentioned problem.

$$
\min (x)=\left\{\begin{array}{c}
\operatorname{minCC}\left(T_{d}, v_{d}, C D, T_{r}\right) \\
\min \mathrm{DT}\left(T_{d}, v_{d}, C D, T_{r}\right) \\
\min \mathrm{EC}\left(T_{d}, v_{d}, C D, T_{r}\right) \\
\min \operatorname{SL}\left(T_{d}, v_{d}, C D, T_{r}\right) \\
\max \mathrm{MG}\left(T_{d}, v_{d}, C D, T_{r}\right) \\
\max \operatorname{VG}\left(T_{d}, v_{d}, C D, T_{r}\right) \\
50{ }^{\circ} \mathrm{C} \leq T_{d} \leq 70{ }^{\circ} \mathrm{C} \\
0.5 \mathrm{~m} / \mathrm{s} \leq v_{d} \leq 2.0 \mathrm{~m} / \mathrm{s} \\
1.5 \mathrm{~mm} \leq C D \leq 5.78 \mathrm{~mm} \\
20^{\circ} \mathrm{C} \leq T_{r} \leq 70^{\circ} \mathrm{C}
\end{array}\right.
$$

The Pareto front for the MOO has been formulated applying nondominated sorting genetic algorithm (NSGA II), implemented in MATLAB Global Optimization Toolbox R2018a. The mentioned algorithm was discussed in [25], whereas NSGA II parameters are following: the crossover function - intermediate, the crossover rate- $85 \%$, the migration-forward, the mutation function-uniform, the mutation rate-15\%, the number of generations-300 number of variables, the Pareto front population fraction -0.8 , the size of the population-20 number of variables, the selection function-Tournament size $=2$.

\section{Results and Discussion}

\subsection{ANN}

Different ANN structures (various transfer functions) for the approximation of the relationship between the variables of dehydration and rehydration $\left(T_{d}, v, C D\right.$, and $\left.T_{r}\right)$ and apple quality parameters $\mathrm{QP}(\mathrm{CC}, \mathrm{MG}, \mathrm{SL}, \mathrm{VG})$, drying time $\mathrm{DT}$, and energy consumption EC were tested (Table 2).

Table 2. ANN architectures tested.

\begin{tabular}{|c|c|c|c|c|c|c|}
\hline \multirow[b]{2}{*}{ ID. } & \multirow{2}{*}{$\begin{array}{l}\text { Activate Function } \\
\text { in the Hidden Layer }\end{array}$} & \multirow{2}{*}{$\begin{array}{l}\text { Number of Neurons in } \\
\text { the Hidden Layer }\end{array}$} & \multirow{2}{*}{$\begin{array}{l}\text { Activate Function } \\
\text { in the Output Layer }\end{array}$} & \multicolumn{3}{|c|}{ Statistical Analysis } \\
\hline & & & & MSE & $\mathbf{R}$ & Adjusted R-Square \\
\hline 1 & \multirow{6}{*}{ log-sigmoid } & 4 & \multirow{3}{*}{ log-sigmoid } & 0.002020 & 0.9914 & 0.9820 \\
\hline 2 & & 6 & & 0.000309 & 0.9914 & 0.9820 \\
\hline 3 & & 8 & & 0.001207 & 0.0990 & 0.0430 \\
\hline 4 & & 4 & \multirow{3}{*}{ pureline } & 0.001664 & 0.9886 & 0.9761 \\
\hline 5 & & 6 & & 0.000825 & 0.9917 & 0.9826 \\
\hline 6 & & 8 & & 0.001983 & 0.9944 & 0.9883 \\
\hline 7 & \multirow{6}{*}{ tansig } & 4 & \multirow{3}{*}{ pureline } & 0.003444 & 0.9853 & 0.9693 \\
\hline 8 & & 6 & & 0.000970 & 0.9931 & 0.9855 \\
\hline 9 & & 8 & & 0.000952 & 0.9950 & 0.9895 \\
\hline 10 & & 4 & \multirow{3}{*}{ log-sigmoid } & 0.003110 & 0.9706 & 0.9390 \\
\hline 11 & & 6 & & 0.004624 & 0.9743 & 0.9466 \\
\hline 12 & & 8 & & 0.000520 & 0.9953 & 0.9901 \\
\hline
\end{tabular}

On account of high adjusted R-square (0.9820), R-value (0.9914), and low MSE (0.0003), the ANN with four neurons in the input layer $\left(T_{d}, v, C D\right.$, and $\left.T_{r}\right)$, six neurons in the hidden layer, and six neurons in the output layer (CC, MG, SL, VG, DT and EC) with log-sigmoid transfer function for hidden and output layers was developed (ID 2 in Table 2). The best validation performance was after 114 iterations (Figure 1a). The values of Adjusted Rsquare and $\mathrm{R}$ were high enough, namely: 0.9841 and 0.9926 for training data, 0.9579 and 0.9865 for validation ones, 0.9685 and 0.9899 for test data, respectively (Figure 1b). 


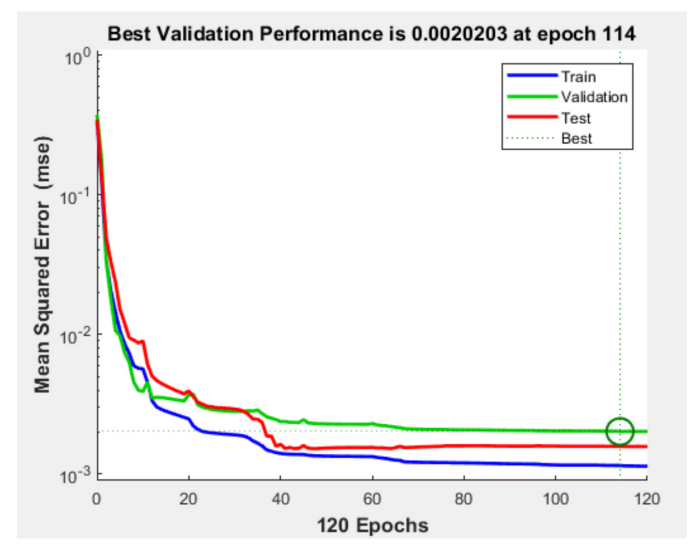

(a)

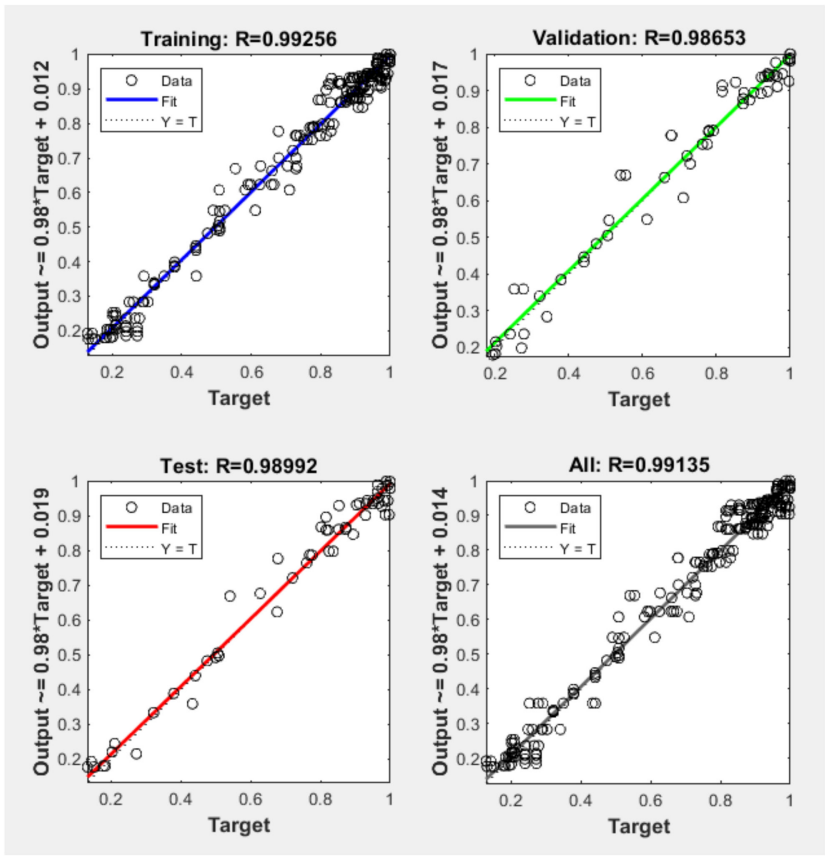

(b)

Figure 1. The best performance of the ANN (a) and the ANN fit goodness (b).

\subsection{MOGA}

Table 3 shows 19 design points of the Pareto optimal set. Figures 2-4 presents the non-dominated points of Pareto front.

Table 3. Pareto optimal sets.

\begin{tabular}{|c|c|c|c|c|c|c|c|c|c|c|}
\hline \multirow{2}{*}{ ID } & \multicolumn{4}{|c|}{ Inputs } & \multicolumn{6}{|c|}{ Outputs } \\
\hline & $T_{d}\left({ }^{\circ} \mathrm{C}\right)$ & $v_{d}(\mathrm{~m} / \mathrm{s})$ & $C D(\mathrm{~mm})$ & $T_{r}\left({ }^{\circ} \mathrm{C}\right)$ & MG (-) & SL (-) & VG (-) & CC (-) & DT (h) & EC (GJ/kg) \\
\hline 1 & 62.44 & 1.2594 & 3.5581 & 56.41 & 2.60 & 0.63 & 4.42 & 7.67 & 4.44 & 283.84 \\
\hline 2 & 66.99 & 1.6903 & 3.1241 & 37.41 & 3.07 & 0.62 & 4.61 & 8.47 & 4.54 & 294.00 \\
\hline 3 & 60.48 & 1.2513 & 4.2814 & 47.66 & 2.07 & 0.57 & 3.85 & 9.74 & 4.57 & 396.82 \\
\hline 4 & 66.64 & 1.4174 & 2.8837 & 50.61 & 3.35 & 0.60 & 4.71 & 9.54 & 4.61 & 248.83 \\
\hline 5 & 64.98 & 1.2986 & 2.6938 & 56.03 & 3.46 & 0.58 & 4.75 & 10.39 & 4.67 & 216.07 \\
\hline 6 & 60.28 & 1.3288 & 3.5348 & 44.76 & 2.53 & 0.63 & 4.38 & 7.60 & 4.68 & 308.62 \\
\hline 7 & 62.11 & 1.6584 & 2.0158 & 47.86 & 3.59 & 0.43 & 4.79 & 14.91 & 4.88 & 342.51 \\
\hline 8 & 55.33 & 1.7493 & 2.5717 & 42.51 & 2.97 & 0.63 & 4.57 & 8.00 & 5.10 & 281.57 \\
\hline 9 & 55.75 & 1.5048 & 2.6483 & 57.37 & 3.04 & 0.63 & 4.60 & 7.96 & 5.36 & 262.38 \\
\hline 10 & 56.10 & 1.2456 & 1.9942 & 59.16 & 3.51 & 0.57 & 4.77 & 11.16 & 5.43 & 159.80 \\
\hline 11 & 53.83 & 1.5361 & 1.5146 & 48.42 & 3.55 & 0.53 & 4.78 & 13.96 & 6.00 & 235.15 \\
\hline 12 & 63.85 & 1.3485 & 5.7152 & 55.26 & 1.83 & 0.43 & 3.19 & 12.40 & 6.24 & 396.98 \\
\hline 13 & 60.81 & 0.7190 & 3.3839 & 45.81 & 2.74 & 0.63 & 4.50 & 7.31 & 6.51 & 261.63 \\
\hline 14 & 64.24 & 1.2258 & 5.6621 & 51.41 & 1.82 & 0.43 & 3.20 & 12.33 & 6.73 & 396.98 \\
\hline 15 & 58.02 & 1.8172 & 5.1563 & 46.69 & 2.43 & 0.43 & 3.84 & 11.77 & 7.06 & 396.98 \\
\hline 16 & 64.45 & 1.1341 & 5.6831 & 47.77 & 1.93 & 0.44 & 3.37 & 12.17 & 7.77 & 396.98 \\
\hline 17 & 59.07 & 0.6460 & 3.2791 & 54.20 & 2.98 & 0.63 & 4.60 & 7.03 & 8.04 & 235.70 \\
\hline 18 & 55.53 & 1.1483 & 1.5125 & 31.98 & 3.26 & 0.61 & 4.57 & 16.41 & 8.08 & 145.40 \\
\hline 19 & 53.81 & 0.9368 & 1.5520 & 41.26 & 2.91 & 0.63 & 4.18 & 17.86 & 8.80 & 138.71 \\
\hline
\end{tabular}




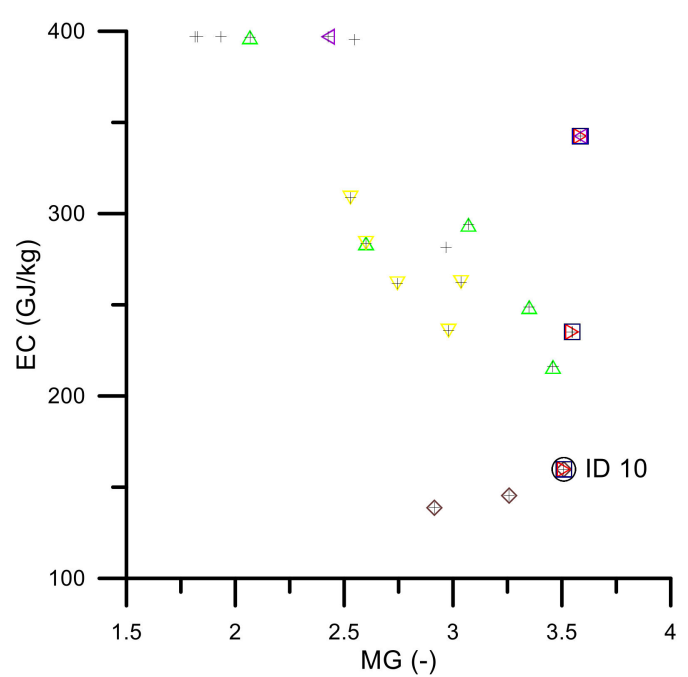

(a)

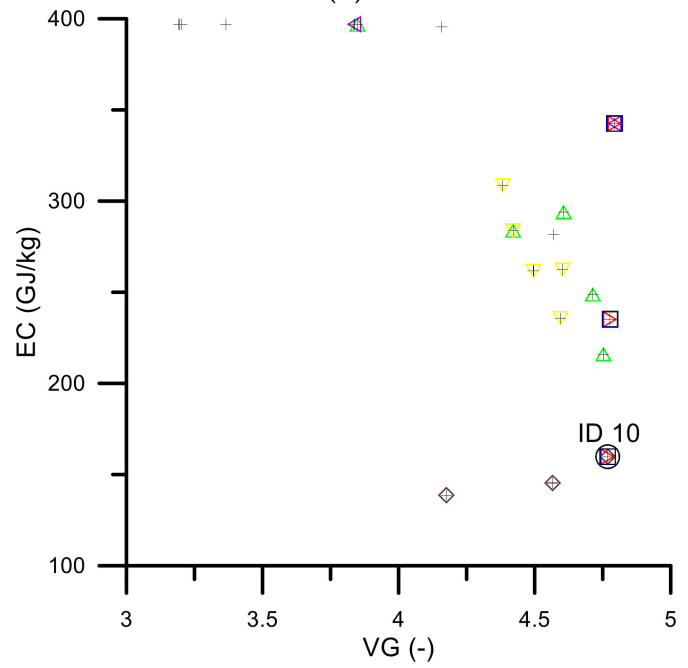

(c)

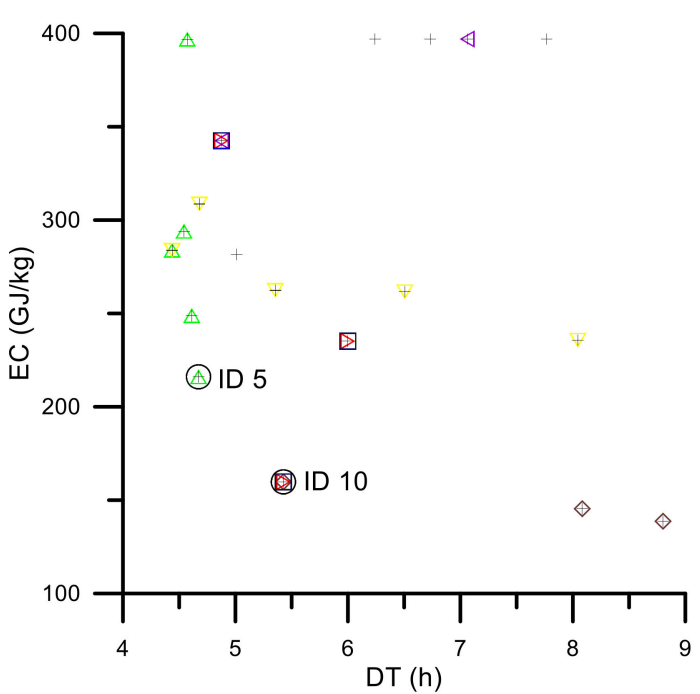

(e)

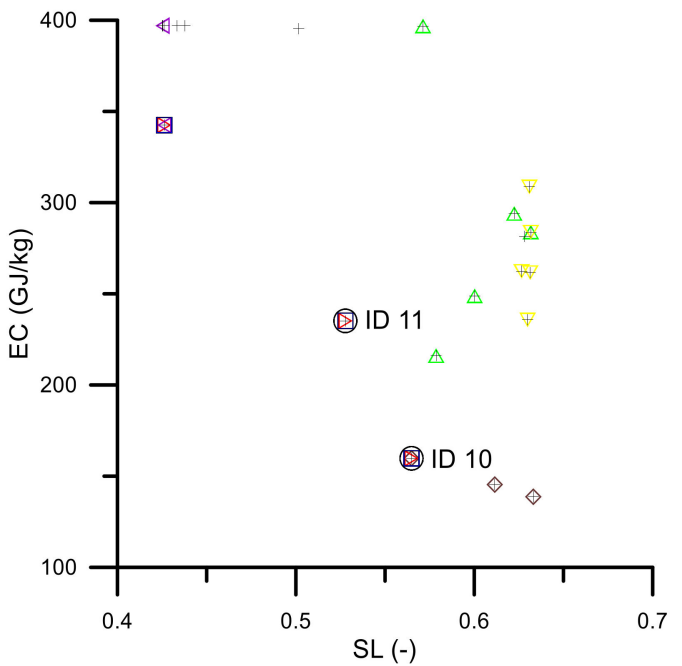

(b)

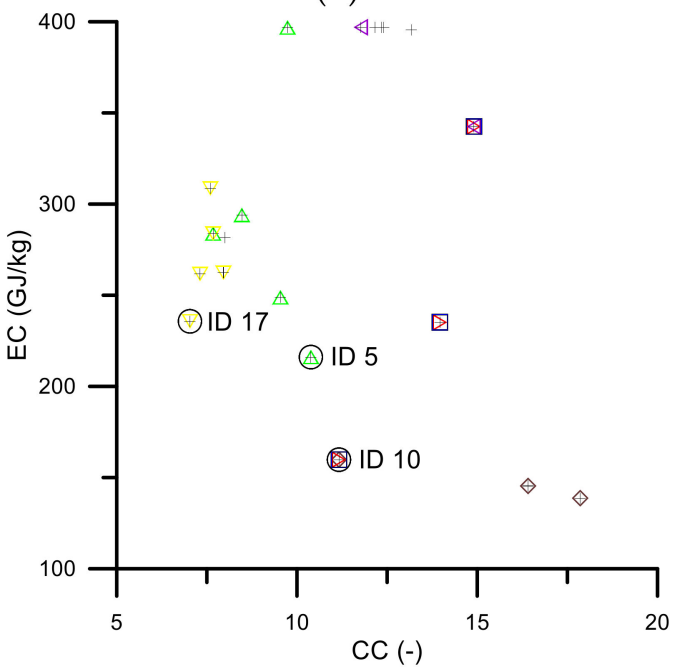

(d)

Figure 2. Pareto fronts: (a) EC-MG, (b) EC-SL, (c) EC-VG, (d) EC-CC, (e) EC-DT; +- data, O-the best solutions, $=\mathrm{MG}_{\max }, \triangle-\mathrm{DT}_{\min },-\mathrm{CC}_{\min },-\mathrm{VG}_{\max }{ }^{-}, 4-\mathrm{SL}_{\min }$. 


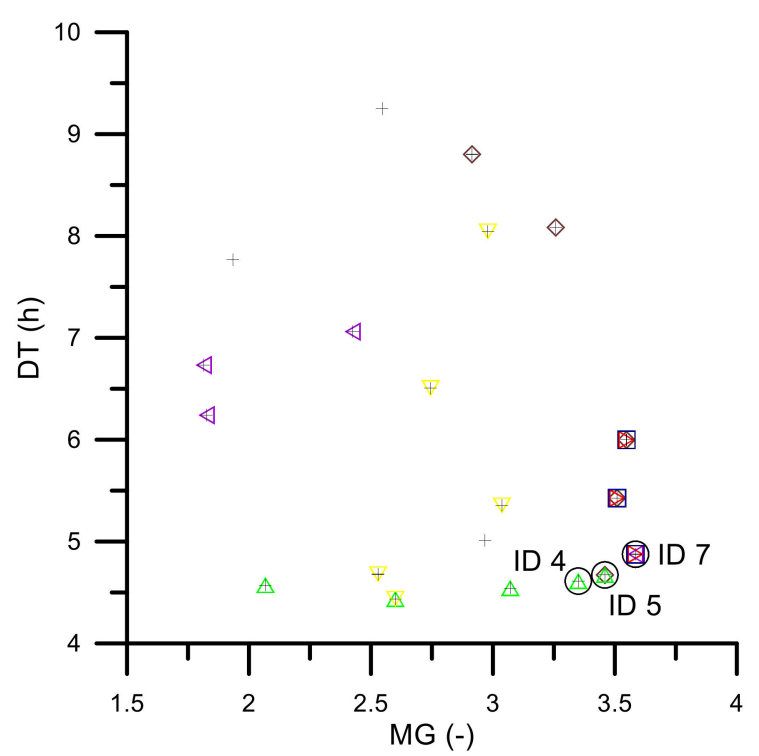

(a)

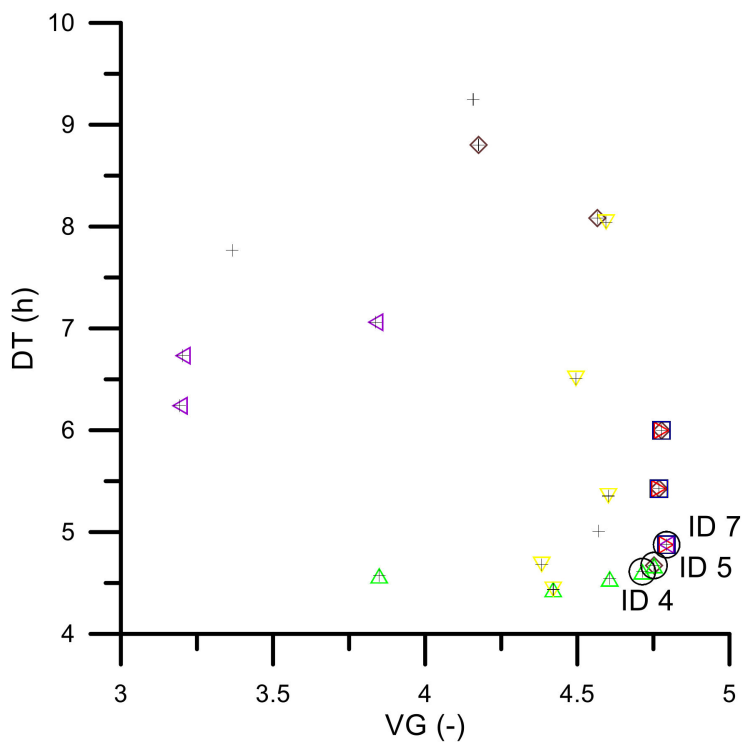

(c)

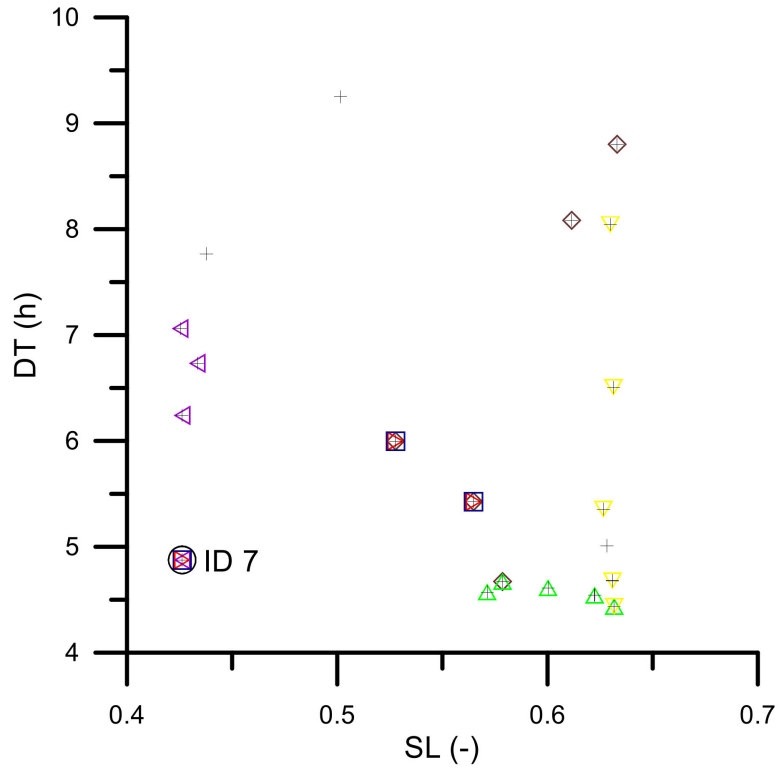

(b)

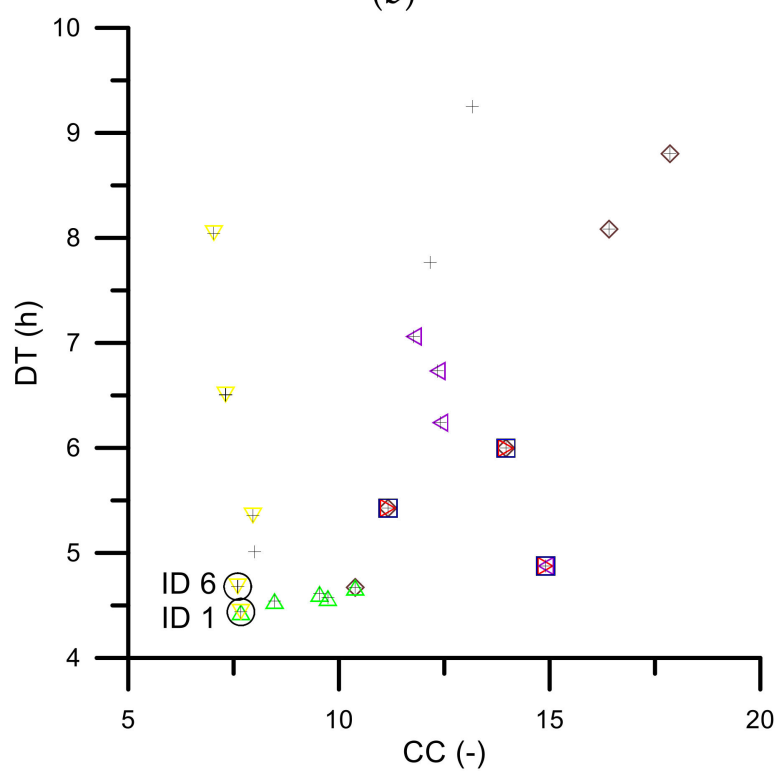

(d)

Figure 3. Pareto fronts: (a) DT-MG, (b) DT-SL, (c) DT-VG, (d) DT-CC; +—data, O-the best solutions, - $-\mathrm{EC}_{\min }$, $-\mathrm{MG}_{\mathrm{max}}$, $\triangle-\mathrm{DT}_{\min },-\mathrm{CC}_{\min },-\mathrm{VG}_{\max }{ }^{-}, 4-\mathrm{SL}_{\min }$. 


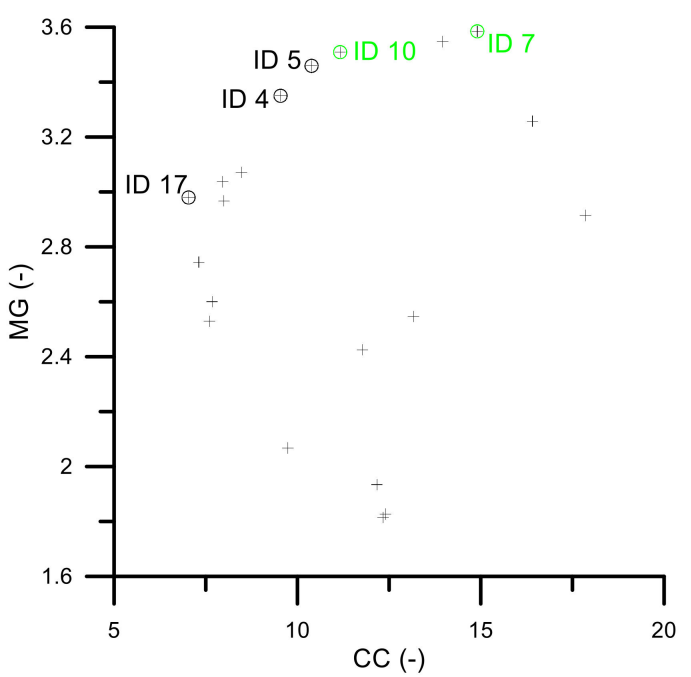

(a)

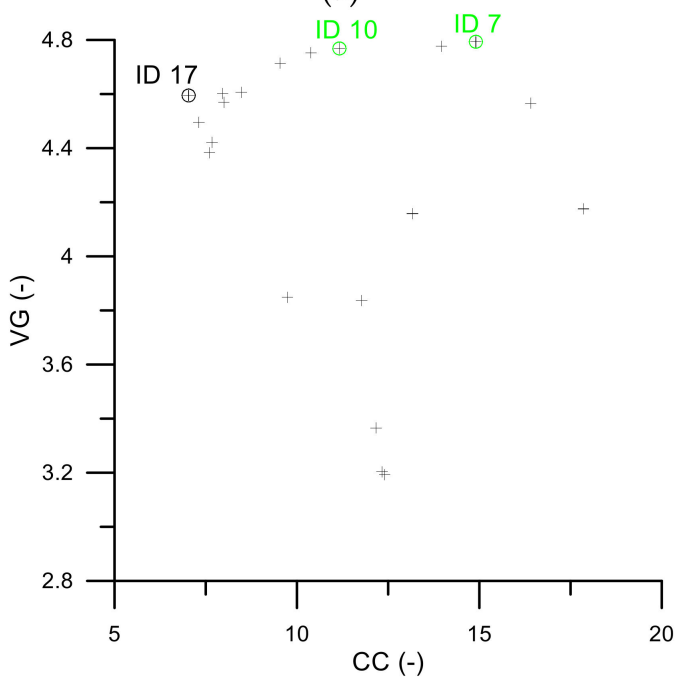

(c)

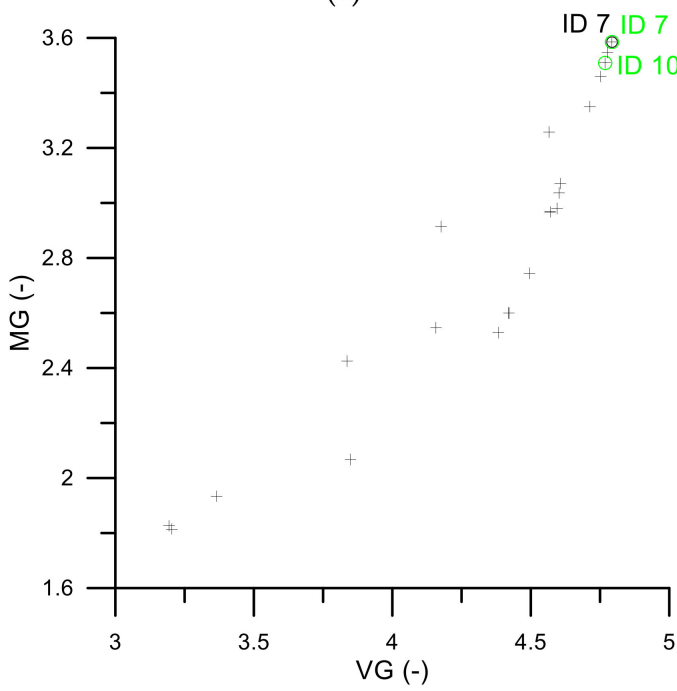

(e)

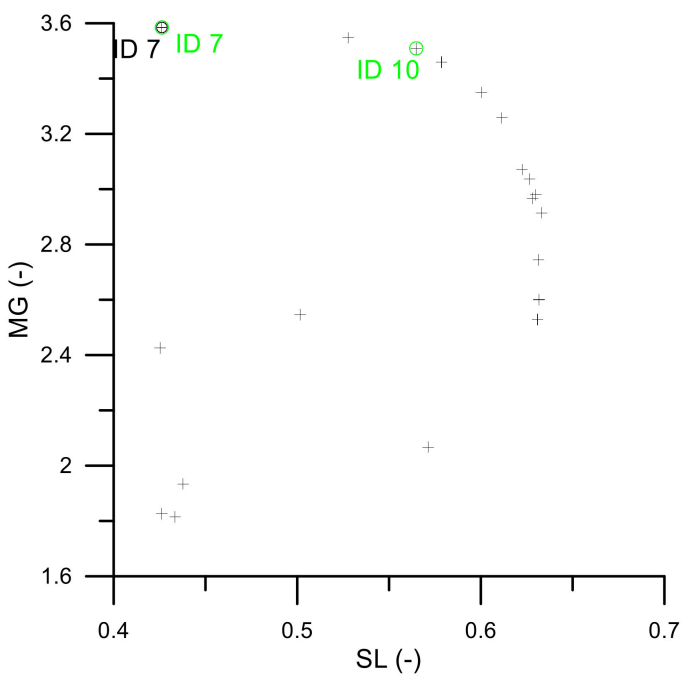

(b)

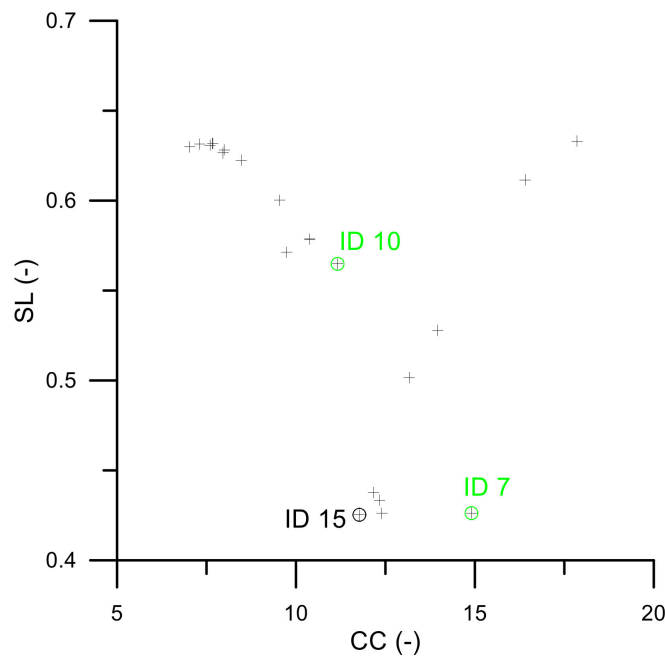

(d)

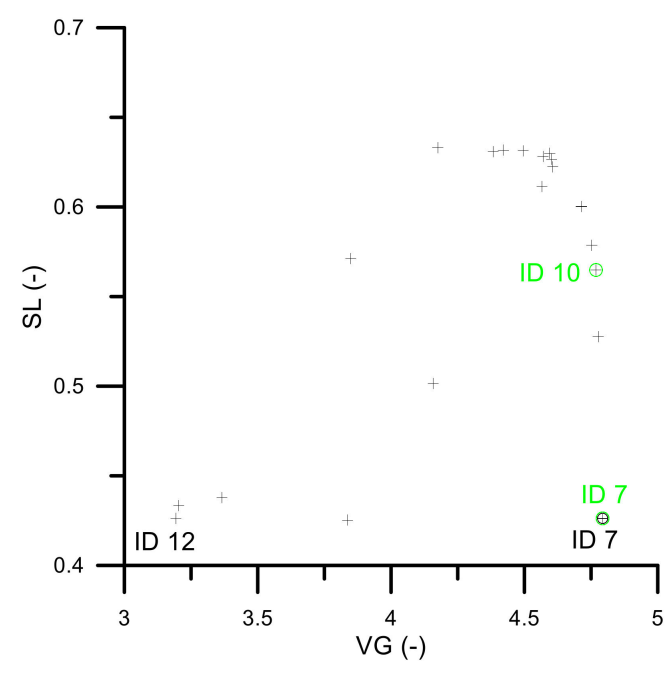

(f)

Figure 4. Pareto fronts: (a) MG-CC, (b) MG-SL, (c) VG-CC, (d) SL-CC, (e) MG-VG, (f) SL-VG; +—data, O-the best solutions, O-ID 7 and ID 10. 
ID10 (Figure 2) was the best solution for the faced optimization task (Equation (8)). It is important to obtain, with possibly low energy consumption, a rehydrated product with acceptable quality parameters from the dried material acquired by drying in a short time.

The solution features the following drying and rehydration parameters: $T_{d}=56.1{ }^{\circ} \mathrm{C}$, $v_{d}=1.25 \mathrm{~m} / \mathrm{s}, C D=2.0 \mathrm{~mm}$, and $T_{r}=59.2^{\circ} \mathrm{C}$. The rehydrated product obtained in such conditions shows $\mathrm{CC}=11.2, \mathrm{DT}=5.4 \mathrm{~h}, \mathrm{MG}=3.51, \mathrm{SL}=0.57, \mathrm{VG}=4.77, \mathrm{EC}=159.8 \mathrm{GJ} / \mathrm{kg}$ (CC 37.0\% higher than $\mathrm{CC}_{\min }$, DT 18.2\% higher than $\mathrm{DT}_{\min }, \mathrm{MG} 2.1 \%$ lower than $\mathrm{MG}_{\max }$, SL $24.7 \%$ higher than $\mathrm{SL}_{\min }, \mathrm{VG}$ 0.5\% lower than $\mathrm{VG}_{\min }$, and $\mathrm{EC} 13.2 \%$ higher than $\mathrm{EC}_{\min }$ ). However, for the EC-SL relation (Figure 2b), we can notice that solution ID11 indicates lower SL values (compared to ID 10) but with a higher EC. Solution ID 11 indicates the following drying and rehydration parameters: $T_{d}=53.8^{\circ} \mathrm{C}, v_{d}=1.54 \mathrm{~m} / \mathrm{s}, C D=1.5 \mathrm{~mm}$, and $T_{r}=48.4^{\circ} \mathrm{C}$, and the obtained rehydrated product shows $\mathrm{CC}=13.96, \mathrm{DT}=6.0 \mathrm{~h}$, $\mathrm{MG}=3.55, \mathrm{SL}=0.53, \mathrm{VG}=4.78, \mathrm{EC}=235.2 \mathrm{GJ} / \mathrm{kg}(\mathrm{CC} 49.60 \%$ and $20.0 \%$ higher, DT $26.8 \%$ and $9.5 \%$ higher, MG 1.0\% lower and 1.1\% higher, SL 19.4\% higher and 7.0\% lower, VG $0.3 \%$ lower and $0.2 \%$ higher, and EC $41.0 \%$ and $32.1 \%$ higher than the minimum or maximum values, respectively, and the value for ID10). For relations EC-CC (Figure 2d) and EC-DT (Figure 2e), we may also accept solution ID5 to be an optimum solution that indicates $T_{d}=65.0{ }^{\circ} \mathrm{C}, v_{d}=1.30 \mathrm{~m} / \mathrm{s}, C D=2.7 \mathrm{~mm}$, and $T_{r}=56.0{ }^{\circ} \mathrm{C}$. The rehydrated product obtained in such conditions shows $\mathrm{CC}=10.39, \mathrm{DT}=4.67 \mathrm{~h}, \mathrm{MG}=3.46, \mathrm{SL}=0.58$, $\mathrm{VG}=4.75, \mathrm{EC}=216.1 \mathrm{GJ} / \mathrm{kg}$ (CC 32.3\% higher and 7.5\% lower, DT 5.1\% higher and 16.2\% lower, MG 3.5\% and 1.4\% lower, SL $26.5 \%$ and $2.4 \%$ higher, VG $0.8 \%$ and $0.3 \%$ lower, and EC $35.8 \%$ and $26.0 \%$ higher than the minimum or maximum values, respectively, and the value for ID10). Additionally, for the ED-CC relation, solution ID $17\left(T_{d}=59.1{ }^{\circ} \mathrm{C}\right.$, $v_{d}=0.65 \mathrm{~m} / \mathrm{s}, C D=3.3 \mathrm{~mm}$, and $T_{r}=54.2{ }^{\circ} \mathrm{C}$ ) shows a lower $\mathrm{CC}(7.0)$ with just a slightly higher EC (compared to ID 5) being $235.7 \mathrm{GJ} / \mathrm{kg}$. For ID17, the CC is the lowest of all values and $58.8 \%$ lower than the CC value obtained for ID 10 . The comparison of the values obtained for ID 17 to the minimum or maximum values, respectively, and the value for ID 10 is as follows: DT $44.8 \%$ and $32.5 \%$ higher, MG $16.9 \%$ and $15.1 \%$ lower, SL $32.5 \%$ and $10.3 \%$ higher, VG $4.1 \%$ and $3.7 \%$ lower, and EC $41.2 \%$ and $32.2 \%$ higher.

ID7 (Figure 3) is the best solution for the faced optimization task (Equation (8)), where it is important to obtain, with possibly short drying time, a rehydrated product with acceptable quality parameters and acceptable consumption of energy used for drying (however, this solution is not optimal for CC). The solution features the following drying and rehydration parameters: $T_{d}=62{ }^{\circ} \mathrm{C}, v=1.66 \mathrm{~m} / \mathrm{s}, C D=2.0 \mathrm{~mm}$, and $T_{r}=47.9^{\circ} \mathrm{C}$. The rehydrated product obtained in such conditions shows $C \mathrm{C}=14.9, \mathrm{DT}=4.9 \mathrm{~h}, \mathrm{MG}=3.59$, $\mathrm{SL}=043, \mathrm{VG}=4.79, \mathrm{EC}=342.5 \mathrm{GJ} / \mathrm{kg}\left(\mathrm{CC} 52.8 \%\right.$ higher than $\mathrm{CC}_{\min }, \mathrm{DT} 9.0 \%$ higher than $\mathrm{DT}_{\min }, \mathrm{MG}=\mathrm{MG}_{\max }, \mathrm{SL} 0.2 \%$ higher than $\mathrm{SL}_{\min }, \mathrm{VG}=\mathrm{VG}_{\min }$, but $\mathrm{EC}$ as much as $59.5 \%$ higher than $\left.\mathrm{EC}_{\min }\right)$.

Given the charts for DT-MG (Figure 3a) and DT-VG (Figure 3c), we can conclude that the optimum solutions also include ID4 and ID5 $\left(T_{d}=66.6^{\circ} \mathrm{C}, v=1.42 \mathrm{~m} / \mathrm{s}, C D=2.9 \mathrm{~mm}\right.$, $T_{r}=50.6{ }^{\circ} \mathrm{C}$, and $T_{d}=65.0{ }^{\circ} \mathrm{C}, v=1.30 \mathrm{~m} / \mathrm{s}, C D=2.7 \mathrm{~mm}, T_{r}=56.0{ }^{\circ} \mathrm{C}$, respectively), but with $\mathrm{EC}_{\mathrm{ID} 4}>\mathrm{EC}_{\mathrm{ID} 5}$. When drying with the indicated parameters, we quickly $(4.6 \mathrm{~h}$ and $4.7 \mathrm{~h}$, respectively) obtain dried material, which then, in the rehydration process, intensively increases both its weight and volume (MG: 3.4 and 3.5; VG: 4.7 and 4.8, respectively). However, energy consumption is high $\left(\mathrm{EC}_{\mathrm{ID} 4}=248.8 \mathrm{GJ} / \mathrm{kg} ; \mathrm{EC}_{\mathrm{ID} 5}=216.1 \mathrm{GJ} / \mathrm{kg}\right)$, being $44.3 \%$ and $35.8 \%$ higher, respectively, compared to $\mathrm{EC}_{\mathrm{min}}$.

Nevertheless, if we consider the chart for DT-CC (Figure 3d), then solutions ID1 and ID6 show such drying and rehydration parameters where the color of the rehydrated product indicates the slightest change compared to the product taken for drying. Solution ID 1 indicates the following drying and rehydration parameters: $T_{d}=62.4^{\circ} \mathrm{C}, v_{d}=1.26 \mathrm{~m} / \mathrm{s}$, $C D=3.6 \mathrm{~mm}$, and $T_{r}=56.4^{\circ} \mathrm{C}$, and the rehydrated product obtained in such conditions shows $\mathrm{CC}=7.67, \mathrm{DT}=4.4 \mathrm{~h}, \mathrm{MG}=2.6, \mathrm{SL}=0.63, \mathrm{VG}=4.42, \mathrm{EC}=283.8 \mathrm{GJ} / \mathrm{kg}(\mathrm{CC}$ 9.1\% higher, $\mathrm{DT}=\mathrm{DT}_{\min }, \mathrm{MG} 27.5 \%$ lower, SL 48.5\% higher, VG 7.8\% lower, and EC $104.6 \%$ higher than the minimum or maximum values, respectively). Solution ID6 (which, 
when compared to ID1, shows a CC 1\% lower with a DT being $5.5 \%$ higher) indicates the following drying and rehydration parameters: $T_{d}=60.3^{\circ} \mathrm{C}, v_{d}=1.33 \mathrm{~m} / \mathrm{s}, C D=3.5 \mathrm{~mm}$, and $T_{r}=44.8^{\circ} \mathrm{C}$, and the rehydrated product obtained in such conditions shows $\mathrm{CC}=7.60$, $\mathrm{DT}=4.7 \mathrm{~h}, \mathrm{MG}=2.5, \mathrm{SL}=0.63, \mathrm{VG}=4.38, \mathrm{EC}=308.6 \mathrm{GJ} / \mathrm{kg}$ (CC 8.1\% higher, DT $5.5 \%$ higher, MG 29.5\% lower, SL 48.3\% higher, VG 8.6\% lower, and EC $122.5 \%$ higher than the minimum or maximum values, respectively).

Considering only the quality parameters of rehydrated apples it could be stated that for the optimization problem expressed using Equation (8), ID 7 and ID 10 are the best solution (Figure 4). However, when comparing the energy consumption for both cases $\left(\mathrm{EC}_{\mathrm{ID}} 7=342.5 \mathrm{GJ} / \mathrm{kg}, \mathrm{EC}_{\mathrm{ID} 10}=159.8 \mathrm{GJ} / \mathrm{kg}\right)$, solution ID 10 should be recommended. Experimental verification proved that maximum error of modeling was lower than $4.86 \%$.

In the previous research about multi-objective normalization of apple drying [31] and drying and rehydration [32] the critical factors-drying time and energy consumption for drying were not considered. Taking these factors into account is very important from the point of view of material acquisition costs. The material should be of the best quality with the lowest possible expenditure for its processing.

The new experimental run $\left(T_{d}=56{ }^{\circ} \mathrm{C}, v_{d}=1.3 \mathrm{~m} / \mathrm{s}, \mathrm{CD}=2.0 \mathrm{~mm}\right.$, and $T_{r}=59{ }^{\circ} \mathrm{C}$ was used to verify the developed model. The experimentally determined values (Table 4) were very close to the predicted values under the same drying and rehydration conditions. The maximum absolute error obtained in the validation process was $4.46 \%$. It proved the consistency and accuracy of the obtained model.

Table 4. Validation results.

\begin{tabular}{ccccccc}
\hline \multirow{2}{*}{ Validation } & \multicolumn{7}{c}{ Quality of Rehydrated Apples } \\
\cline { 2 - 7 } & MG & SL & VG & CC & DT & EC \\
\hline Experimental values $\left(y_{e i}\right)$ & 3.48 & 0.59 & 4.68 & 11.7 & 5.3 & 162 \\
Predicted values $\left(y_{p i}\right)$ & 3.51 & 0.57 & 4.77 & 11.2 & 5.4 & 159.8 \\
Errors $=\frac{y_{e i}-y_{p i}}{y_{p i}} \cdot 100 \%$ & 0.85 & 3.5 & 1.88 & 4.46 & 1.85 & 1.38 \\
\hline
\end{tabular}

\section{Conclusions}

The effect of drying (drying temperature $T_{d}: 50-70{ }^{\circ} \mathrm{C}$, air velocity $v_{d}: 0.5-1 \mathrm{~m} / \mathrm{s}$, characteristic dimension $C D: 1.5-5.78 \mathrm{~mm}$ ) and rehydration (rehydration temperature $T_{r}: 20-70{ }^{\circ} \mathrm{C}$ ) parameters on the quality of rehydrated apples: color change (CC), mass gain ratio (MG), solid loss ratio (SL), and volume gain ratio (VG) and on the drying time (DT) and energy consumption (EC) required for drying of apple were investigated.

A multi-objective optimization algorithm, based on Pareto optimization, genetic algorithm and artificial neural network, was developed. Optimization objectives for simultaneous maximization, MG and VG, and for minimization, CC, SL, DT, EC, were used, whereas the objective functions were determined by application of an artificial neural network. The Pareto optimal set was formulated applying non-dominated sorting genetic algorithm II.

The parameters of apple drying and rehydration processes, derived from optimization of both processes, can be recommended for the industry application. Use of the following parameters: $T_{d}=56.1^{\circ} \mathrm{C}, v_{d}=1.3 \mathrm{~m} / \mathrm{s}, C D=2.0 \mathrm{~mm}$, and $T_{r}=59.2^{\circ} \mathrm{C}$ results in 3.51 for MG, 0.57 for SL, 4.77 for VG, 11.2 for CC, $5.4 \mathrm{~h}$ for DT, and $159.8 \mathrm{GJ} / \mathrm{kg}$ for EC. Conducting both processes under received conditions allowed to obtain rehydrated apple with properties similar to the raw material properties with comparatively shorter drying time and lower energy consumption for drying.

Author Contributions: R.W. data analysis, methodology, modeling, optimization; A.K. manuscript writing, manuscript critical revision; K.G. research proposal topic, data analysis, visualization, manuscript writing. All authors have read and agreed to the published version of the manuscript.

Funding: This research received no external funding. 
Institutional Review Board Statement: Not applicable.

Informed Consent Statement: Not applicable.

Data Availability Statement: Not applicable.

Conflicts of Interest: The authors declare no conflict of interest.

\section{References}

1. Bora, G.C.; Pathak, R.; Ahmadi, M.; Mistry, P. Image Processing Analysis to Track Colour Changes on Apple and Correlate to Moisture Content in Drying Stages. Food Qual. Saf. 2018, 2, 105-110. [CrossRef]

2. Sinha, N.K. Apples. In Handbook of Fruits and Fruit Processing; Hui, Y.H., Ed.; Blackwell Publishing: Ames, IA, USA, 2006; pp. 263-278. ISBN 978-0-470-27773-7.

3. Park, Y.; Chang, Y.-S.; Park, J.-H.; Yang, S.-Y.; Chung, H.; Jang, S.-K.; Choi, I.-G.; Yeo, H. Energy Efficiency of Fluidized Bed Drying for Wood Particles. J. Korean Wood Sci. Technol. 2016, 44, 821-827. [CrossRef]

4. Syahrul, S.; Hamdullahpur, F.; Dincer, I. Exergy Analysis of Fluidized Bed Drying of Moist Particles. Exergy Int. J. 2002, 2, 87-98. [CrossRef]

5. Midilli, A.; Kucuk, H. Energy and Exergy Analyses of Solar Drying Process of Pistachio. Energy 2003, 28, 539-556. [CrossRef]

6. Motevali, A.; Minaei, S.; Khoshtagaza, M.H. Evaluation of Energy Consumption in Different Drying Methods. Energy Convers. Manag. 2011, 52, 1192-1199. [CrossRef]

7. Nazghelichi, T.; Aghbashlo, M.; Kianmehr, M.H. Optimization of an Artificial Neural Network Topology Using Coupled Response Surface Methodology and Genetic Algorithm for Fluidized Bed Drying. Comput. Electron. Agric. 2011, 75, 84-91. [CrossRef]

8. Tremblay, C.; Zhou, D. A Study of Efficient Drying Parameters for Bed Dryers. In Proceedings of the 2nd International Conference on Fluid Flow, Heat and Mass Transfer, Ottawa, ON, Canada, 30 April-1 May 2015; p. 179.

9. Chaudhari, A.R.; Kostha, V.; Upadhyay, J.B. Optimum Energy Requirement of Fluidized Bed Dryer for Drying of Khoa. Int. J. Chem. Stud. 2018, 6, 40-44.

10. Zlatanović, I.; Komatina, M.; Antonijević, D. Low-temperature convective drying of apple cubes. Appl. Therm. Eng. 2013, 53, 114-123. [CrossRef]

11. Seiiedlou, S.; Ghasemzadeh, H.R.; Hamdami, N.; Talati, F.; Moghaddam, M. Convective Drying of Apple: Mathematical Modeling and Determination of some Quality Parameters. Int. J. Agric. Biol. 2010, 12, 171-178.

12. Figiel, A. Dehydration of apples by a combination of convective and vacuum-microwave drying. Pol. J. Food Nutr. Sci. 2007, 57, 131-135.

13. Chong, C.H.; Figiel, A.; Law, C.L.; Wojdyło, A. Combined Drying of Apple Cubes by Using of Heat Pump, Vacuum-Microwave, and Intermittent Techniques. Food Bioprocess Technol. 2014, 7, 975-989. [CrossRef]

14. Pasławska, M.; Stępień, B.; Nawirska-Olszańska, A.; Maślankowski, R.; Rydzak, L. Effect of Vacuum Impregnation on Drying Kinetics and Selected Quality Factors of Apple Cubes. Int. J. Food Eng. 2017, 13, 20160309. [CrossRef]

15. Diamante, L.M.; Yamaguchi, Y. Response surface methodology for optimisation of hot air drying of blackcurrant concentrate infused apple cubes. Int. Food Res. J. 2012, 19, 353-362.

16. Assis, F.R.; Morais, R.M.S.C.; Morais, A.M.M.B. Rehydration of osmotically pre-treated apple cubes dried by hot air, microwave, and freeze-drying. Acta Alim. 2018, 47, 315-323. [CrossRef]

17. Kraśniewska, K.; Ścibisz, I.; Gniewosz, M.; Mitek, M.; Pobiega, K.; Cendrowski, A. Effect of Pullulan Coating on Postharvest Quality and Shelf-Life of Highbush Blueberry (Vaccinium Corymbosum L.). Materials 2017, 10, 965. [CrossRef]

18. Zhang, J.-W.; Liu, H.-H.; Yang, H.; Yang, L. Drying Characteristics of Eucalyptus Urophylla $\times$ E. Grandis with Supercritical $\mathrm{CO}_{2}$. Materials 2020, 13, 3989. [CrossRef] [PubMed]

19. Górnicki, K.; Kaleta, A. Drying Curve Modelling of Blanched Carrot Cubes under Natural Convection Condition. J. Food Eng. 2007, 82, 160-170. [CrossRef]

20. Nayak, C.A.; Suguna, K.; Rastogi, N.K. Combined Effect of Gamma-Irradiation and Osmotic Treatment on Mass Transfer during Rehydration of Carrots. J. Food Eng. 2006, 74, 134-142. [CrossRef]

21. Lewicki, P.P. Some Remarks on Rehydration of Dried Foods. J. Food Eng. 1998, 36, 81-87. [CrossRef]

22. Funebo, T.; Ohlsson, T. Microwave-Assisted Air Dehydration of Apple and Mushroom. J. Food Eng. 1998, 38, 353-367. [CrossRef]

23. Sacilik, K.; Elicin, A.K. The Thin Layer Drying Characteristics of Organic Apple Slices. J. Food Eng. 2006, 73, 281-289. [CrossRef]

24. Krokida, M.K.; Philippopoulos, C. Rehydration of Dehydrated Foods. Dry. Technol. 2005, 23, 799-830. [CrossRef]

25. McMinn, W.A.M.; Magee, T.R.A. Quality and Physical Structure of a Dehydrated Starch-Based System. Dry. Technol. 1997, 15, 1961-1971. [CrossRef]

26. Mulet, A.; Cárcel, J.A.; Sanjuán, N.; Bon, J. New Food Drying Technologies-Use of Ultrasound. Food Sci. Technol. Int. 2003, 9 , 215-221. [CrossRef]

27. Holland, J.H. Adaptation in Natural and Artificial Systems; University of Michigan Press: Ann Arbor, MI, USA, 1975.

28. Goldberg, D. Genetic Algorithms in Search, Optimization, and Machine Learning; Addison-Wesley: Boston, MA, USA, 1989.

29. Michalewicz, Z. Genetic Algorithms + Data Structures = Evolution Programs; Springer: Berlin, Germany, 1992.

30. Davis, L. Handbook of Genetic Algorithms; Van Nostrand Reinhold: New York, NY, USA, 1991. 
31. Winiczenko, R.; Górnicki, K.; Kaleta, A.; Martynenko, A.; Janaszek-Mańkowska, M.; Trajer, J. Multi-Objective Optimization of Convective Drying of Apple Cubes. Comput. Electron. Agric. 2018, 145, 341-348. [CrossRef]

32. Winiczenko, R.; Górnicki, K.; Kaleta, A.; Janaszek-Mańkowska, M.; Choińska, A.; Trajer, J. Apple Cubes Drying and Rehydration. Multiobjective Optimization of the Processes. Sustainability 2018, 10, 4126. [CrossRef]

33. Darvishi, H.; Farhudi, Z.; Behroozi-Khazaei, N. Multi-Objective Optimization of Savory Leaves Drying in Continuous InfraredHot Air Dryer by Response Surface Methodology and Desirability Function. Comput. Electron. Agric. 2020, $168,105112$. [CrossRef]

34. Luikov, A.V. Analytical Heat Diffusion Theory; Academic: New York, NY, USA, 1968.

35. Colorimetry, 3rd ed; Internationale Beleuchtungskommission, Technical Report; CIE, Central Bureau: Vienna, Austria, 2004; ISBN 978-3-901906-33-6.

36. Schanda, J. CIE Colorimetry. In Colorimetry: Understanding the CIE System; Schanda, J., Ed.; John Wiley \& Sons, Inc.: Hoboken, NJ, USA, 2007; pp. 25-78. ISBN 978-0-470-17563-7.

37. Motevli, A.; Minaei, S.; Banakar, A.; Ghobadian, B.; Khoshtaghaza, M.H. Comparison of energy parameters in various dryers. Energy Convers. Manag. 2014, 87, 711-725. [CrossRef]

38. Nadi, F.; Górnicki, K.; Winiczenko, R. A novel optimization algorithm for Echium amoenum petals drying. Appl. Sci. 2020, 10, 8387. [CrossRef]

39. Vieira, M.G.A.; Estrella, L.; Rocha, S.C.S. Energy Efficiency and Drying Kinetics of Recycled Paper Pulp. Dry. Technol. 2007, 25, 1639-1648. [CrossRef]

40. Fausett, L.V. Fundamentals of Neural Networks: Architectures, Algorithms, and Applications; Prentice-Hall: Englewood Cliffs, NJ, USA, 1994; ISBN 978-0-13-334186-7.

41. Barr, A.; Feigenbaum, E. The Handbook of Artificial Intelligence; Addison-Wesley: New York, NY, USA, 1989 ; Volume 3.

42. Kung, S. Digital Neural Networks; Prentice-Hall: Englewood Cliffs, NJ, USA, 1993.

43. Omid, M.; Baharlooei, A.; Ahmadi, H. Modeling drying kinetics of pistachio nuts with multi-layer feed-forward neural network. Dry. Technol. 2009, 27, 1069-1077. [CrossRef] 